\title{
Clinical factors associated with venous thromboembolism risk in patients undergoing craniotomy
}

\author{
Kristopher T. Kimmell, MD, and Babak S. Jahromi, MD, PhD \\ Department of Neurosurgery, University of Rochester Medical Center, Rochester, New York
}

OBJECT Patients undergoing craniotomy are at risk for developing venous thromboembolism (VTE). The safety of anticoagulation in these patients is not clear. The authors sought to identify risk factors predictive of VTE in patients undergoing craniotomy.

METHODS The authors reviewed a national surgical quality database, the American College of Surgeons National Surgical Quality Improvement Program. Craniotomy patients were identified by current procedural terminology code. Clinical factors were analyzed to identify associations with VTE.

RESULTS Four thousand eight hundred forty-four adult patients who underwent craniotomy were identified. The rate of VTE in the cohort was 3.5\%, including pulmonary embolism in $1.4 \%$ and deep venous thrombosis in $2.6 \%$. A number of factors were found to be statistically significant in multivariate binary logistic regression analysis, including craniotomy for tumor, transfer from acute care hospital, age $\geq 60$ years, dependent functional status, tumor involving the CNS, sepsis, emergency surgery, surgery time $\geq 4$ hours, postoperative urinary tract infection, postoperative pneumonia, on ventilator $\geq 48$ hours postoperatively, and return to the operating room. Patients were assigned a score based on how many of these factors they had (minimum score 0 , maximum score 12). Increasing score was predictive of increased VTE incidence, as well as risk of mortality, and time from surgery to discharge.

CONCLUSIONS Patients undergoing craniotomy are at low risk of developing VTE, but this risk is increased by preoperative medical comorbidities and postoperative complications. The presence of more of these clinical factors is associated with progressively increased VTE risk; patients possessing a VTE Risk Score of $\geq 5$ had a greater than 20 -fold increased risk of VTE compared with patients with a VTE score of 0.

http://thejns.org/doi/abs/10.3171/2014.10.JNS14632

KEY WORDS craniotomy; ACS NSQIP; venous thromboembolism; quality; outcomes; diagnostic and operative techniques

$\mathrm{T}$ HE new millennium has seen a dramatic transformation in health care delivery in the US. Cost of health care, in particular as a reflection of percentage of gross domestic product, has increased sharply in the past decade. ${ }^{26}$ A number of measures have been implemented to attempt to curb this trend, many of which have been focused on the quality of care delivered. The Centers for Medicare and Medicaid, in conjunction with other organizations like the Joint Commission and the Leapfrog Group, have focused on particular episodes of care as targets of quality improvement. It is with this goal in mind that the Surgical Care Improvement Project (SCIP) was implemented in 2006. A key target of SCIP is prophylaxis against venous thromboembolism (VTE). With hospital reimbursement now tied directly to VTE prevention, hospital administrators have made prevention of VTE events a focus of new surgical protocols. However, this has created opposing incentives, whereby institutional desire to prevent reportable VTE episodes runs counter to surgeons' wishes to avoid hemorrhagic complications.

In the neurosurgical literature, previous studies have reported a wide range of the incidence of VTE. . $^{2,6,8-8-12,14 \text {, }}$ 16,17,19,20,24,27,29,31,32,36-38,47-49,52 The most recent meta-analysis of VTE prophylaxis in neurosurgical patients concluded

ABBREVIATIONS ACS = American College of Surgeons; $\mathrm{ASA}=$ American Society of Anesthesiologists; $\mathrm{BMI}=$ body mass index; $\mathrm{Cl}=$ confidence interval; $\mathrm{CPT}=\mathrm{current}$ procedural terminology; DVT = deep venous thrombosis; MI = myocardial infarction; NSQIP = National Surgical Quality Improvement Program; OR = odds ratio; $\mathrm{PE}=$ pulmonary embolism; RCT = randomized controlled trial; SCIP = Surgical Care Improvement Project; $T I A=$ transient ischemic attack; UTI = urinary tract infection; VTE = venous thromboembolism.

SUBMITTED March 31, 2014. ACCEPTED October 22, 2014.

INCLUDE WHEN CITING Published online December 12, 2014; DOI: 10.3171/2014.10.JNS14632.

DISCLOSURE The authors report no conflict of interest concerning the materials or methods used in this study or the findings specified in this paper. 
that bleeding complications attributable to prophylaxis are nearly equal to symptomatic VTE events prevented, making the routine use of chemical prophylaxis in neurosurgical patients "far from clear cut." 24 The authors contend that it is difficult to compare the VTE complication prevented by prophylaxis to the hemorrhagic complication caused by chemoprophylaxis, as each has different clinical consequences. They also highlight the challenge of analyzing pooled risk of neurosurgical patients from randomized trials and meta-analyses, as patients with traumatic brain injury have a different, and likely greater, risk of VTE than patients undergoing elective cranial surgery. Furthermore, the author of the seminal randomized controlled trial comparing compression devices to low-molecular-weight heparin ${ }^{2}$ later suggested in a review that heparin products should be used in craniotomy patients "with caution."

Other authors have argued that when the risk of chemoprophylaxis is compared with the risk of VTE for patients undergoing craniotomy, using systematic decision analysis, the risks outweigh the benefits of routinely utilizing chemoprophylaxis. ${ }^{14}$ However, despite the relatively rare occurrence of VTE, previous studies have suggested that there may be subpopulations of patients at increased risk of VTE events, and who might therefore show net benefit with VTE prophylaxis. ${ }^{12}$ The most recent clinical guidelines from the American College of Chest Physicians recommended routine chemoprophylaxis only for those patients considered to be "at very high risk" for VTE. ${ }^{21}$ However, the definition of such patients remains open to interpretation and the level of evidence to support this recommendation is low (Grade 2C).

There are likely a variety of factors that contribute to VTE risk in neurosurgical patients. This has been suggested in previous studies but without reaching statistical significance. Taken in sum, the risk-benefit ratio for chemical VTE prophylaxis in neurosurgical patients is marginal. However, there likely exist categories of patients at increased risk of VTE for whom the risk-benefit calculation is markedly different than for the baseline neurosurgical population.

We set out to examine clinical factors associated with VTE using the American College of Surgeons (ACS) National Surgical Quality Improvement Program (NSQIP) database (http://site.acsnsqip.org). ${ }^{28}$ The NSQIP database documents a large number of baseline health characteristics and premorbid conditions for surgical patients as well as postoperative complications. For the purposes of our analysis, the years 2006-2010 were selected and analyzed.

\section{Methods}

\section{Baseline Univariate Analysis}

Four thousand eight hundred forty-four patients from 2006 to 2010 were identified as craniotomy cases based on primary current procedural terminology (CPT) code. For ordinal and nominal variables, univariate 2-tailed chisquare analysis, and subsequent Fisher's exact tests where applicable, were performed to identify clinical factors correlating with a VTE event. Continuous variables were compared with VTE occurrence using a 2-tailed Student t-test.
The following clinical factors were available in the ACSNSQIP dataset and subjected to analysis: sex; race; CPT code; inpatient status; transfer status; age; anesthesia used; level of resident supervision; height; weight; body mass index (BMI); history of diabetes; history of smoking; history of alcohol use; history of dyspnea; do not resuscitate status; functional status prior to surgery; ventilator dependent prior to surgery; pneumonia prior to surgery; ascites prior to surgery; history of esophageal varices; history of congestive heart failure; history of myocardial infarction (MI); history of previous percutaneous coronary intervention; history of angina; history of hypertension requiring medication; history of peripheral vascular disease; history of limb pain at rest or gangrene; history of renal failure; on dialysis preoperatively; impaired sensorium preoperatively; in coma for more than 24 hours preoperatively; hemiplegia, paraplegia, or quadriplegia prior to surgery; history of transient ischemic attack (TIA) or stroke prior to surgery; tumor involving the CNS; disseminated cancer prior to surgery; open wound or wound infection prior to surgery; steroid use for a chronic disease; greater than $10 \%$ weight loss prior to surgery; history of a bleeding disorder; blood transfusion of more than 4 units; history of chemotherapy or radiotherapy for malignancy; history of systemic sepsis; pregnant at time of surgery; surgery in 30 days prior to current surgery; preoperative laboratory values; other related CPT codes; surgeon who dictated case; highest level or training of resident; emergency case; wound classification; American Society of Anesthesiologists (ASA) classification; airway trauma during surgery; Mallampati scale; ${ }^{33}$ number of red blood cell transfusions during surgery; duration of anesthesia; duration of surgery and total operating room time; intraoperative complication; postoperative wound infection; postoperative pneumonia; postoperative unplanned intubation; postoperative pulmonary embolism (PE); postoperative prolonged ventilation greater than 48 hours; postoperative renal insufficiency or failure; postoperative urinary tract infection (UTI); postoperative stroke; postoperative coma lasting longer than 24 hours; postoperative cardiac arrest requiring cardiopulmonary resuscitation; postoperative MI; postoperative blood transfusions; postoperative deep venous thrombosis (DVT); postoperative sepsis or septic shock; and return to the operating room.

Each clinical factor with a $\mathrm{p}$ value $\leq 0.05$ in univariate chi-square analysis was considered statistically significant. Odds ratios (ORs) were calculated when appropriate. Based on primary CPT code, procedures that were performed for a tumor diagnosis (CPT codes 61510, 61512, 61518, 61519, 61520, 61521, 61526, 61545, 61546, and 61575) were also identified. A number of variables, based on univariate analysis, were converted to binary variables (transfer status-from acute care hospital $=1$; functional status-dependent $=1$; bleeding disorder-yes $=$ 1 ; ASA classification-Score 4-5 = 1; craniotomy-tumor $=$ 1 ; age $\geq 60=1$ ). In addition, based on sensitivity analysis, operating room time was divided into 2 categories: less than 4 hours and greater than or equal to 4 hours. These conversions were performed to calculate ORs as well as to strengthen the multivariate regression model. 


\section{Development of VTE Risk Score}

Those preoperative and intraoperative clinical factors with $p$ values $\leq 0.05$ were then subjected to a forward, stepwise, multivariate binary logistical regression analysis (entry level $=0.05$, exit $=0.1$ ) to identify clinical factors independently correlated with VTE events. Interactions between covariates were analyzed using chi-square analysis and several interactions were noted. These interactions were included stepwise in iterations of multivariate regression; however, inclusion of these interactions did not impact the robustness of the multivariate model. Next, postoperative complications associated with VTE were subjected independently to multivariate logistic regression while controlling for preoperative and intraoperative factors. This analysis excluded patients in whom the complication of interest occurred after VTE. Interactions between postoperative covariates were analyzed. Not surprisingly, there were significant interactions between postoperative complications, particularly the pulmonary complications (postoperative pneumonia, and on a ventilator $\geq 48$ hours). However, inclusion of these interactions in multivariate regression did not significantly impact the results of the overall model and so they were excluded from final analysis. Factors significant at $p<0.05$ in multivariate regression were then added to a generalized linear model predictive of VTE to maximize the goodness of fit of the model based on Nagelkerke pseudo- $\mathrm{R}^{2}$, and receiver operating characteristic curve. A total of 12 factors were included in the final multivariate model (Table 1). Each of these factors was then converted to a binary score of 0 or 1 , with 1 representing the presence of that factor. Patients were then assigned a score on the basis of how many factors they had. The lowest score possible was 0 and highest possible score was 12 . In this series, the range of scores for VTE risk was 0-9 (mean $2.1 \pm 1.5$ [SD], median 2.0). Because of the small number of patients with high VTE scores, for the purposes of analysis the patients were divided into groups based on VTE scores of $0,1,2,3,4$, and $\geq 5$. Next, the VTE Risk Score was compared with rate of

TABLE 1. Factors significant after multivariate analysis

\begin{tabular}{lcc}
\hline \multicolumn{1}{c}{ Factor } & $p$ Value & OR $(95 \% \mathrm{Cl})$ \\
\hline Preop & & \\
\hline Transfer from acute care hospital & $<0.001$ & $3.31(1.95-5.60)$ \\
\hline Preop sepsis & $<0.001$ & $3.06(2.07-4.53)$ \\
\hline Emergency case & $<0.001$ & $2.99(2.16-4.13)$ \\
\hline Dependent functional status & $<0.001$ & $2.87(2.10-3.91)$ \\
\hline Age $\geq 60$ yrs & 0.006 & $1.56(1.15-2.12)$ \\
\hline Tumor involving CNS & 0.011 & $1.49(1.10-2.04)$ \\
\hline Craniotomy for tumor & 0.029 & $1.42(1.05-1.93)$ \\
\hline Intraop & & \\
\hline Operation time $\geq 4$ hrs & 0.004 & $1.67(1.20-2.32)$ \\
\hline Postop & & \\
\hline Pneumonia & $<0.001$ & $6.38(4.24-9.61)$ \\
\hline On ventilator $\geq 48$ hrs & $<0.001$ & $6.04(4.30-8.48)$ \\
\hline UTI & $<0.001$ & $3.82(2.40-6.07)$ \\
\hline Return to operating room & $<0.001$ & $2.68(1.80-3.97)$ \\
\hline
\end{tabular}

VTE and with 30-day mortality rate using 2-tailed chisquare analysis, and compared with the number of days until discharge using the Kruskal-Wallis test. All statistical analysis was performed using SPSS software (version 18.0, IBM).

\section{Results}

The rate of VTE in the cohort was 3.5\%, including PE in $1.4 \%$ and DVT in $2.6 \%$. Of the 69 patients with a PE in the cohort, 42 (60.9\%) did not have an associated diagnosis of DVT. DVT and PE were both associated with an increased time to discharge ( $p<0.0001$ for both variables). Notably, neither all VTE, nor DVT or PE, was statistically associated with increased 30-day mortality (Table 2).

Preoperative characteristics associated with VTE were transfer from an acute care facility, age $\geq 60$ years, dependent functional status, ventilator dependence, previous cardiac surgery, chronic steroid use, systemic inflammatory response syndrome/sepsis, hypertension, impaired sensorium, coma $>24$ hours, hemiplegia, TIA, stroke, tumor involving the CNS, and bleeding disorder. Operative characteristics associated with VTE were craniotomy for tumor, emergency case, ASA Class 4-5, and surgery time $\geq 4$ hours. Postoperative events associated with VTE included superficial surgical site infection, pneumonia, unplanned reintubation, ventilation $\geq 48$ hours, UTI, stroke, coma, sepsis/septic shock, and return to the operating room.

Those factors significant in univariate analysis were subjected to multivariate binary regression analysis, which indicated that transfer from an acute care hospital, age $\geq 60$ years, dependent functional status, craniotomy for tumor, tumor involving the CNS, preoperative sepsis, emergency case, surgical time longer than 4 hours, postoperatively on ventilator longer than 48 hours, postoperative pneumonia, postoperative UTI, and return to the operating room were independent risk factors for VTE (Table 1). Each of these factors was incorporated into the VTE Risk Score, with 1 point assigned for each factor. The VTE Risk Score was notably predictive for VTE incidence, with a rate of $0.5 \%$ for a score of 0 and a rate of $14.7 \%$ for a score $\geq 5$ (p $<0.001$ ), and PE and DVT individually as well (Fig. 1). Additionally, the VTE Risk Score was associated with increased number of days from surgery to discharge ( $\mathrm{p}<$ 0.0001). An increasing VTE Risk Score was also associated with increased mortality $(\mathrm{p}<0.0001$; Table 3$)$.

A receiver operating characteristic curve was created to assess the ability of the VTE Risk Score to predict VTE; the area under the curve was 0.761 (95\% confidence interval [CI] 0.725-0.798).

TABLE 2. DVT and PE events and mortality rate

\begin{tabular}{lcc}
\hline \multicolumn{1}{c}{ Group } & Total Patients & Mortality Rate (\%) \\
\hline Overall cohort & 4844 & 5.0 \\
\hline No VTE & 4674 & 5.0 \\
\hline VTE & 170 & 4.1 \\
\hline DVT & 128 & 3.1 \\
\hline PE & 69 & 5.8 \\
\hline
\end{tabular}


TABLE 3. VTE Risk Score and VTE/PE/DVT rates, days from surgery to discharge, and mortality rate

\begin{tabular}{ccccccc}
\hline $\begin{array}{c}\text { VTE Risk } \\
\text { Score }\end{array}$ & $\begin{array}{c}\text { No. of Patients } \\
(\% \text { of total) }\end{array}$ & VTE Rate $(\%)^{*}$ & PE Rate $(\%)^{*}$ & DVT Rate $(\%)^{*}$ & $\begin{array}{c}\text { Mean Days From Surgery } \\
\text { to Discharge } \pm \text { SD* }^{*}\end{array}$ & Mortality Rate $(\%)^{*}$ \\
\hline 0 & $756(15.6)$ & 0.5 & 0.4 & 0.1 & $2.8 \pm 5.5$ & 0 \\
\hline 1 & $1182(24.4)$ & 1.2 & 0.5 & 0.8 & $3.8 \pm 4.6$ & 0.8 \\
\hline 2 & $1108(22.9)$ & 2.1 & 0.8 & 1.6 & $5.2 \pm 8.0$ & 2.3 \\
\hline 3 & $924(19.1)$ & 4.1 & 1.7 & 2.6 & $7.1 \pm 10.0$ & 6.3 \\
\hline 4 & $526(10.9)$ & 7.6 & 2.9 & 6.1 & $10.2 \pm 14.1$ & 14.6 \\
\hline$>5$ & $348(7.2)$ & 14.7 & 5.7 & 12.4 & $19.1 \pm 24.7$ & 20.1 \\
\hline Overall & 4844 & 3.5 & 1.4 & 2.6 & $6.4 \pm 11.2$ & 5.0 \\
\hline
\end{tabular}

* All data in column are statistically significant $(p<0.001)$.

\section{Discussion}

Venous thromboembolism prophylaxis remains a challenging problem for neurosurgeons, in particular for patients undergoing craniotomy. In nearly half a century of trials examining the problem, no definitive conclusion has been reached. In the most recent meta-analysis, Hamilton and colleagues found that the number of symptomatic VTEs prevented by prophylaxis was approximately equal to the number of hemorrhages caused. ${ }^{24}$ Collen and colleagues in their meta-analysis also concluded that surgeons' concern over increased hemorrhage risk with the use of heparin products appears warranted. ${ }^{12}$ Several decision analyses have concluded that the risk of hemorrhage for patients undergoing craniotomy ${ }^{14}$ or who have traumatic cranial injuries ${ }^{50}$ argues against the routine use of chemical prophylaxis.

Collen and colleagues also suggested that there may be patients with an increased risk of VTE at baseline, in particular older patients and patients with a primary neo- plastic diagnosis. Khaldi and colleagues screened a wideranging group of patients for DVT at their institution. They found that length of surgery was associated with incidence of lower-extremity DVT in a linear fashion. ${ }^{29}$ One challenge of performing subgroup analysis on the risk of VTE in neurosurgical patients is the lack of adequate sample sizes to perform such analyses that would reach statistically and clinically meaningful conclusions.

One goal of our analysis was to attempt to quantify and stratify risk of VTE in subpopulations of neurosurgical patients based on clinical factors. We chose the NSQIP dataset for the large number of cases and wide variety of clinical factors that could be analyzed. When comparing our findings, in particular rates of VTE, to previously published randomized controlled trials (RCTs) of chemical prophylactic agents, there is some amount of discrepancy in reported rates. It is difficult to compare the rates published in these trials to recent registry reports. For one reason, several of the previous RCTs were published prior to the routine use of mechanical prophylaxis in surgical

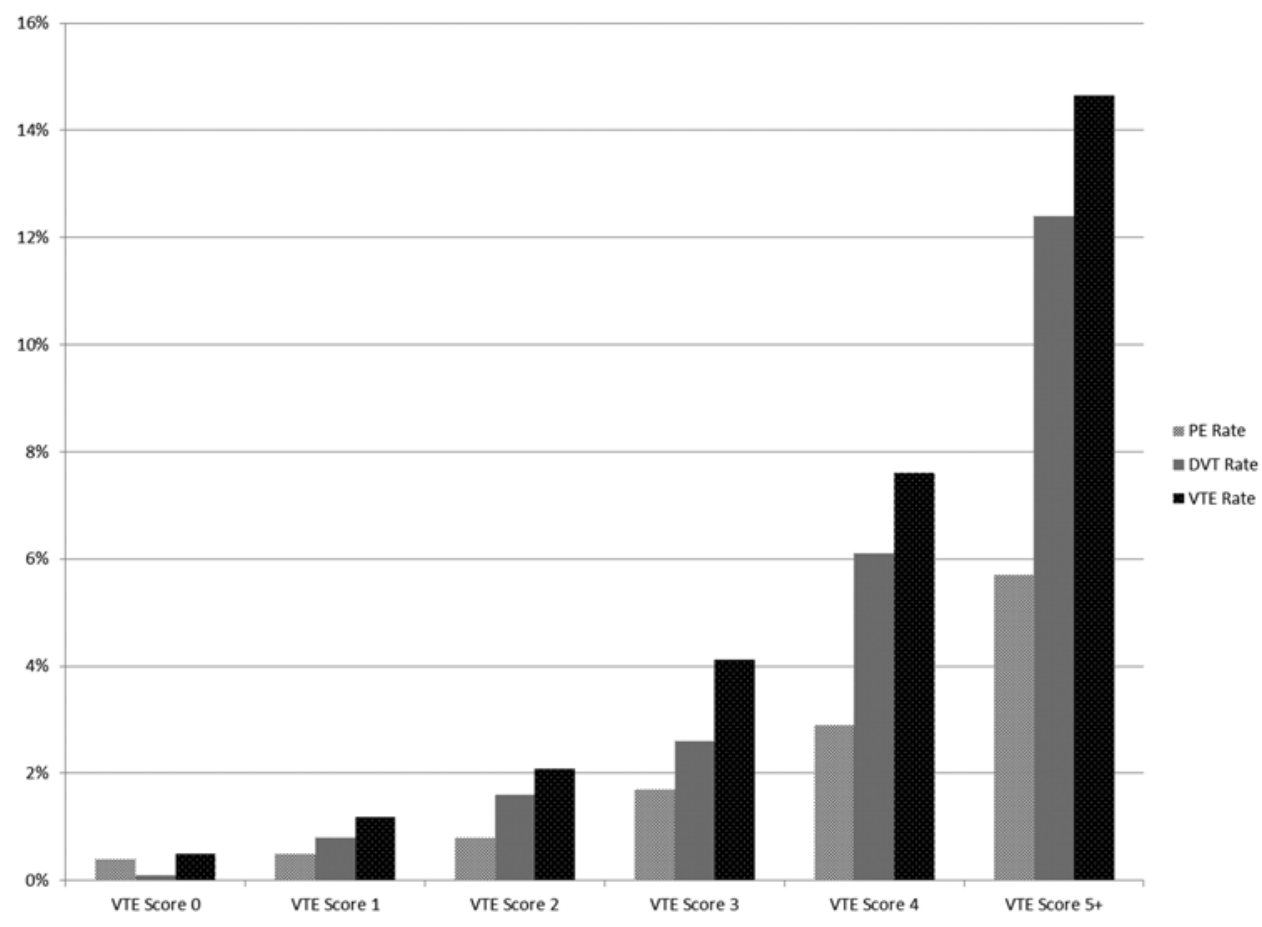

FIG. 1. Rates of PE, DVT, and VTE, based on VTE Risk Score. 
patients. Three of the 6 studies analyzed by Hamilton and colleagues had no mechanical prophylaxis in the control group..$^{11,13,34}$ Only 1 of the 6 used pneumatic compression stockings in the control group; ${ }^{16}$ interestingly, this was the only trial that did not demonstrate lower VTE rates in patients given chemical prophylaxis. A review of more recently published trials that have examined VTE rates in neurosurgical patients demonstrates lower rates of VTE in these studies. ${ }^{13,17,19,20,32,44}$ Patel and colleagues recently performed screening ultrasonography at admission on more than 1000 consecutive patients at their institution and reported a DVT rate of $2.8 \% .^{42}$

Another limitation of previous RCTs is the methods and timing of diagnosis of VTE. For example, venography and $\mathrm{I}^{125}$ fibrinogen were used to diagnose DVTs in 4 of the 6 trials, , 2,11,13,34 tests that are not routinely used today, although they may be more sensitive than Doppler ultrasonography. Moreover, all patients underwent screening for DVT regardless of symptoms. Hamilton and colleagues discuss these limitations at length in their metaanalysis, highlighting that many of the DVTs diagnosed were likely asymptomatic. ${ }^{24}$ Given Hamilton's statement that only $10 \%-20 \%$ of DVTs are symptomatic, and that in Agnelli's trial documented symptomatic DVTs and PEs represented only $37 \%$ of all VTE events, the percentages of symptomatic VTE in previous randomized studies begins to resemble the rate of clinically significant VTEs captured by the ACS NSQIP. The ACS NSQIP specifies in their definitions that a DVT must be confirmed by diagnostic imaging and must require treatment with anticoagulation or intravenous filter placement to be counted. ${ }^{5}$ Although even an asymptomatic proximal leg DVT confers increased risk of mortality at 90 days, the same is not true for distal leg DVTs. ${ }^{56}$ The management of infrapopliteal DVTs remains a management controversy even in the hematology literature. . $^{39,40}$

The rise of administrative databases and clinical registries may help to overcome some of the limitations of previous RCTs by providing more robust and larger datasets for analysis. The ACS-NSQIP database is a pioneer among surgical quality registries. Begun in the Department of Veterans Affairs hospital system in the 1990s as an initiative to decrease surgical morbidity and mortality, it was expanded nationally in the early 2000s. There have been several papers documenting the impact of the ACS NSQIP on surgical quality at the hospital level. ${ }^{22,23}$ The advantage of a clinician-designed surgical registry is the inclusion of a wide variety of factors that contribute to surgical risk and outcomes. New registries focused on neurosurgical patients are on the horizon, with the National Neurosurgery Quality and Outcomes Database ( $\left.\mathrm{N}^{2} \mathrm{QOD}\right)$ launched for lumbar spine disorders in 2012, a registry for cervical disorders following shortly thereafter, and a cerebrovascular module in preparation.

A number of studies have been published in recent years using the NSQIP to examine VTE rates in general surgery, ${ }^{41,55}$ breast surgery, ${ }^{53}$ surgical oncology, ${ }^{35}$ $\operatorname{vascular}^{15,45,51}$ and urological ${ }^{54}$ procedures, and factors associated with VTE incidence. Comparing these findings with our analysis, the studies have identified many of the same factors contributing to VTE risk: increased surgery time, dependent functional status, on ventilator $\geq 48$ hours postoperatively, return to the operating room, increased age, procedure type, and active cancer. Some notable differences between our results and other studies are, for example, that the rate of VTE in our neurosurgical cohort was greater than the rate in any other study. Also, disseminated cancer, postoperative stroke, chronic steroid use, and increased ASA score were identified as correlating with VTE in other studies; although these were significant in univariate analysis, they lost significance in multivariate analysis in our study. Other studies demonstrated increased risk with increased BMI, but this was not significant in our cohort.

We have demonstrated, through our analysis of the ACS-NSQIP dataset of craniotomy procedures, that a number of clinical factors are associated with VTE risk. In particular, several preoperative factors are strongly correlated with VTE risk, and the presence of more of these factors increases the incidence of VTE compared with low-risk categories of patients. Older patients, patients undergoing craniotomy for tumor, and patients undergoing emergency craniotomy procedures are all at increased risk of VTE. Not surprisingly, other postoperative complications are also strongly associated with VTE.

Given that for the large majority of patients in this cohort $(63 \%)$ with a VTE Risk Score of 0-2, the risk of VTE is $\leq 2 \%$, the risk-benefit ratio of using chemical prophylaxis would favor the use of nonpharmacological measures. Risk stratification to assess increased risk of VTE has been examined in oncology..$^{30}$ The use of clinical factors, coupled with biomarkers of VTE such as D-dimer ${ }^{43}$ or microparticles, ${ }^{18}$ may lead to clinical trials examining more aggressive prophylaxis measures in high-risk patients. ${ }^{58}$

Our findings raise several important questions. Although many screening and prophylaxis studies have focused on the detection, prevention, and treatment of DVT, it is unclear what impact these measures have on PE prevention. ${ }^{3}$ It is worth noting that in our dataset, the majority of PEs occurred without an associated DVT diagnosis. Khaldi and colleagues noted a reduction in DVT diagnoses with more aggressive prophylaxis measures but without an associated decrease in PE. ${ }^{29}$ Even in the hematology literature, there is controversy over the management of lower-extremity DVTs, especially those that arise in infrapopliteal veins. ${ }^{39,40}$ The ACS-NSQIP dataset does not provide information regarding the location of DVT events documented.

In the current health delivery environment, quality metrics are often outlined by nonclinicians who do not have an adequate appreciation of the challenges of managing particular groups of patients. This has the unintended consequence of focusing on preventing events that may or may not impact the overall quality of patient care..$^{25,46}$ The SCIP targets were initially designed to identify key aspects of perioperative patient care that should be addressed in all patients. The ultimate goal of the SCIP measures, as outlined by the Joint Commission, is "improving surgical care by significantly reducing surgical complications" (http:// www.jointcommission.org/surgical_care_improvement_ project/). However, a recent study highlighted the fact that for Medicare patients admitted for surgery during the era 
of SCIP, complication rates have actually increased. ${ }^{57}$ It is not likely that the complication rates are increasing but rather that increased vigilance is leading to increased diagnosis, a trend that has been noted by some authors. ${ }^{\text {? }}$

After several years of implementation, the success of the SCIP measures in the prevention of complications has not been well established. Moreover, the true impact of the "quality" of patient care, defined in terms of the presence or absence of a VTE, is not clear. In our analysis of the ACS-NSQIP dataset, VTE occurrence had no negative impact on the 30-day mortality rate for patients undergoing craniotomy. There was an association with increased length of hospital stay. However, patients who were sicker were more likely to have a VTE, which may indicate other causes for their increased hospital stay. Were patients in the hospital longer due to their VTE, or were VTEs more likely to be diagnosed in these patients because they were in the hospital longer?

An additional unintended consequence of focusing on VTE prevention in the management of surgical patients is the diagnosis of DVT that would have otherwise not been clinically detected. Bilimoria and colleagues have shown a significant surveillance bias of VTE in surgical patients with the advent of the SCIP measures.7 Other authors have proposed the use of routine lower-extremity ultrasound examinations near the time of admission for all neurosurgical patients, to screen for DVT. ${ }^{42}$ Given that there is some latitude regarding the management of lower-extremity DVT, the benefit of ruling out DVT as a diagnosis in every neurosurgical patient is unclear. Although Patel and colleagues point to the fact that there were no PEs in their cohort, given the findings of Khaldi and colleagues ${ }^{29}$ as well as our findings, this may be a random effect and not necessarily a result of their screening protocol.

Given the grave consequences of a PE for a patient admitted for elective surgery, it is ultimately this complication that surgeons wish to prevent. While chemical prophylaxis does appear to decrease the risk of PE, it does not eliminate the risk. As we have shown, there are a number of factors intrinsic to patients that increase the risk of VTE, some modifiable and some not. It will require future clinical trials to determine if more aggressive surveillance and prophylaxis measures are of benefit for patients at increased risk of VTE.

Our study has a number of limitations. First and foremost, our study represents a retrospective analysis of a surgical cohort and is subject to selection bias. There are also the limitations of analysis based on a large database, including concerns about data quality and fidelity. However, the ACS NSQIP has very rigorous data quality requirements and has been shown to impact quality of surgical care in other studies. ${ }^{22}$ In addition, there is some selection bias inherent in the NSQIP dataset, as larger academic institutions with rigorous research programs and quality improvement initiatives are disproportionately represented in the database. Furthermore, analysis based on a dataset is limited by what data has been recorded. A notable deficiency of the ACS-NSQIP dataset is that whether prophylaxis was used is not recorded and so there is no way to assess its effect on the findings. There are also no data for hemorrhagic complications in these patients. As mentioned previously, there is no distinction made in location of thrombus in the DVT category. In future studies, it would be worth examining the natural history and association with PE of proximal versus distal lower-extremity DVT, as well as upper-extremity DVT. Another limitation of the ACS NSQIP is that the use of central venous catheters and duration of insertion are not recorded. This has been shown in other studies to be associated with increased VTE risk and would be worth examination.

There are limitations to our conclusions as well. Although our findings are statistically significant, they represent a very imperfect predictive model of VTE and mortality as represented by low correlation factor (pseudo- $\mathrm{R}^{2}$ ) for both analyses (0.04 for VTE and 0.08 for mortality). However, while this value may appear statistically insignificant, it is clinically relevant. It is unlikely that any combination of factors would lead to a perfect correlation with VTE due to the overall rarity of VTE events. However, stratifying patient risk of VTE from $0.5 \%$ to $15 \%$ is clinically relevant. Our findings highlight some important associations with VTE that may inform future clinical investigations. An additional limitation of our model is that it has not been validated. Future investigations will seek to validate the utility of this risk score in predicting VTE in other neurosurgical cohorts.

\section{Conclusions}

The risk of VTE in patients undergoing craniotomy is modified by a number of clinical factors, including those intrinsic to the patient, operative factors, and postoperative complications. We have demonstrated that a simple risk score can predict the risk of VTE in patients undergoing craniotomy. Future studies should focus on validating this risk score and examining whether more aggressive surveillance and prophylaxis in high-risk patients can substantively attenuate their risk of VTE.

\section{References}

1. Agnelli G: Prevention of venous thromboembolism in surgical patients. Circulation 110 (24 Suppl 1):IV4-IV12, 2004

2. Agnelli G, Piovella F, Buoncristiani P, Severi P, Pini M, D'Angelo A, et al: Enoxaparin plus compression stockings compared with compression stockings alone in the prevention of venous thromboembolism after elective neurosurgery. $\mathbf{N}$ Engl J Med 339:80-85, 1998

3. Altom LK, Deierhoi RJ, Grams J, Richman JS, Vick CC, Henderson WG, et al: Association between Surgical Care Improvement Program venous thromboembolism measures and postoperative events. Am J Surg 204:591-597, 2012

4. Altschuler E, Moosa H, Selker RG, Vertosick FT Jr: The risk and efficacy of anticoagulant therapy in the treatment of thromboembolic complications in patients with primary malignant brain tumors. Neurosurgery 27:74-77, 1990

5. American College of Surgeons National Surgical Quality Improvement Program: User Guide for the 2011 Participant Use Data File. Chicago: American College of Surgeons, 2012 (http://site.acsnsqip.org/wp-content/ uploads/2012/03/2011-User-Guide_Final.pdf) [Accessed October 26, 2014]

6. Barnett HG, Clifford JR, Llewellyn RC: Safety of mini-dose heparin administration for neurosurgical patients. J Neurosurg 47:27-30, 1977

7. Bilimoria KY, Chung J, Ju MH, Haut ER, Bentrem DJ, Ko 
CY, et al: Evaluation of surveillance bias and the validity of the venous thromboembolism quality measure. JAMA 310:1482-1489, 2013

8. Boström S, Holmgren E, Jonsson O, Lindberg S, Lindström B, Winsö I, et al: Post-operative thromboembolism in neurosurgery. A study on the prophylactic effect of calf muscle stimulation plus dextran compared to low-dose heparin. Acta Neurochir (Wien) 80:83-89, 1986

9. Browd SR, Ragel BT, Davis GE, Scott AM, Skalabrin EJ, Couldwell WT: Prophylaxis for deep venous thrombosis in neurosurgery: a review of the literature. Neurosurg Focus 17(4):E1, 2004

10. Bucci MNPS, Papadopoulos SM, Chen JC, Campbell JA, Hoff JT: Mechanical prophylaxis of venous thrombosis in patients undergoing craniotomy: a randomized trial. Surg Neurol 32:285-288, 1989

11. Cerrato D, Ariano C, Fiacchino F: Deep vein thrombosis and low-dose heparin prophylaxis in neurosurgical patients. J Neurosurg 49:378-381, 1978

12. Collen JF, Jackson JL, Shorr AF, Moores LK: Prevention of venous thromboembolism in neurosurgery: a metaanalysis. Chest 134:237-249, 2008

13. Constantini S, Kanner A, Friedman A, Shoshan Y, Israel Z, Ashkenazi E, et al: Safety of perioperative minidose heparin in patients undergoing brain tumor surgery: a prospective, randomized, double-blind study. J Neurosurg 94:918-921, 2001

14. Danish SF, Burnett MG, Ong JG, Sonnad SS, MaloneyWilensky E, Stein SC: Prophylaxis for deep venous thrombosis in craniotomy patients: a decision analysis. Neurosurgery 56:1286-1294, 2005

15. Davenport DL, Xenos ES: Deep venous thrombosis after repair of nonruptured abdominal aneurysm. J Vasc Surg 57:678-683.e1, 2013

16. Dickinson LD, Miller LD, Patel CP, Gupta SK: Enoxaparin increases the incidence of postoperative intracranial hemorrhage when initiated preoperatively for deep venous thrombosis prophylaxis in patients with brain tumors. Neurosurgery 43:1074-1081, 1998

17. Frim DM, Barker FG II, Poletti CE, Hamilton AJ: Postoperative low-dose heparin decreases thromboembolic complications in neurosurgical patients. Neurosurgery 30:830-833, 1992

18. Geddings JE, Mackman N: Tumor-derived tissue factor-positive microparticles and venous thrombosis in cancer patients. Blood 122:1873-1880, 2013

19. Gerlach R, Scheuer T, Beck J, Woszczyk A, Seifert V, Raabe A: Risk of postoperative hemorrhage after intracranial surgery after early nadroparin administration: results of a prospective study. Neurosurgery 53:1028-1035, 2003

20. Goldhaber SZ, Dunn K, Gerhard-Herman M, Park JK, Black PM: Low rate of venous thromboembolism after craniotomy for brain tumor using multimodality prophylaxis. Chest 122:1933-1937, 2002

21. Gould MK, Garcia DA, Wren SM, Karanicolas PJ, Arcelus JI, Heit JA, et al: Prevention of VTE in nonorthopedic surgical patients: Antithrombotic Therapy and Prevention of Thrombosis, 9th ed: American College of Chest Physicians Evidence-Based Clinical Practice Guidelines. Chest 141 (2 Suppl):e227S-277S, 2012 (Erratum in Chest 141:1369, 2012)

22. Guillamondegui OD, Gunter OL, Hines L, Martin BJ, Gibson W, Clarke PC, et al: Using the National Surgical Quality Improvement Program and the Tennessee Surgical Quality Collaborative to improve surgical outcomes. J Am Coll Surg 214:709-716, 2012

23. Hall BL, Hamilton BH, Richards K, Bilimoria KY, Cohen ME, Ko CY: Does surgical quality improve in the American College of Surgeons National Surgical Quality Improvement Program: an evaluation of all participating hospitals. Ann Surg 250:363-376, 2009
24. Hamilton MG, Yee WH, Hull RD, Ghali WA: Venous thromboembolism prophylaxis in patients undergoing cranial neurosurgery: a systematic review and meta-analysis. Neurosurgery 68:571-581, 2011

25. Hawn MT, Vick CC, Richman J, Holman W, Deierhoi RJ, Graham LA, et al: Surgical site infection prevention: time to move beyond the surgical care improvement program. Ann Surg 254:494-501, 2011

26. Heffler S, Smith S, Keehan S, Clemens MK, Won G, Zezza M: Health spending projections for 2002-2012. Health Aff (Millwood) Suppl Web Exclusives:W3-54-W3-65, 2003

27. Henwood PC, Kennedy TM, Thomson L, Galanis T, Tzanis GL, Merli GJ, et al: The incidence of deep vein thrombosis detected by routine surveillance ultrasound in neurosurgery patients receiving dual modality prophylaxis. J Thromb Thrombolysis 32:209-214, 2011

28. Ingraham AM, Richards KE, Hall BL, Ko CY: Quality improvement in surgery: the American College of Surgeons National Surgical Quality Improvement Program approach. Adv Surg 44:251-267, 2010

29. Khaldi A, Helo N, Schneck MJ, Origitano TC: Venous thromboembolism: deep venous thrombosis and pulmonary embolism in a neurosurgical population. J Neurosurg 114:40-46, 2011

30. Khorana AA: Risk assessment and prophylaxis for VTE in cancer patients. J Natl Compr Canc Netw 9:789-797, 2011

31. Levi AD, Wallace MC, Bernstein M, Walters BC: Venous thromboembolism after brain tumor surgery: a retrospective review. Neurosurgery 28:859-863, 1991

32. Macdonald RL, Amidei C, Baron J, Weir B, Brown F, Erickson RK, et al: Randomized, pilot study of intermittent pneumatic compression devices plus dalteparin versus intermittent pneumatic compression devices plus heparin for prevention of venous thromboembolism in patients undergoing craniotomy. Surg Neurol 59:363-374, 2003

33. Mallampati SR, Gatt SP, Gugino LD, Desai SP, Waraksa B, Freiberger D, et al: A clinical sign to predict difficult tracheal intubation: a prospective study. Can Anaesth Soc J 32:429434, 1985

34. Melon E, Keravel Y, Gaston A, Huet Y, Combes S, The NEURONOX Group: Deep venous thrombosis prophylaxis by low molecular weight heparin in neurosurgical patients. Anesthesiology 75 (Suppl 1):A214, 1991 (Abstract)

35. Merkow RP, Bilimoria KY, McCarter MD, Cohen ME, Barnett CC, Raval MV, et al: Post-discharge venous thromboembolism after cancer surgery: extending the case for extended prophylaxis. Ann Surg 254:131-137, 2011

36. Misra M, Roitberg B, Ebersole K, Charbel FT: Prevention of pulmonary embolism by combined modalities of thromboprophylaxis and intensive surveillance protocol. Neurosurgery 54:1099-1103, 2004

37. Muchmore JH, Dunlap JN, Culicchia F, Kerstein MD: Deep vein thrombophlebitis and pulmonary embolism in patients with malignant gliomas. South Med J 82:1352-1356, 1989

38. Nurmohamed MT, van Riel AM, Henkens CM, Koopman MM, Que GT, d'Azemar P, et al: Low molecular weight heparin and compression stockings in the prevention of venous thromboembolism in neurosurgery. Thromb Haemost 75:233-238, 1996

39. Palareti G: How I treat isolated distal deep vein thrombosis (IDDVT). Blood 123:1802-1809, 2014

40. Palareti G, Schellong S: Isolated distal deep vein thrombosis: what we know and what we are doing. J Thromb Haemost 10:11-19, 2012

41. Pannucci CJ, Shanks A, Moote MJ, Bahl V, Cederna PS, Naughton NN, et al: Identifying patients at high risk for venous thromboembolism requiring treatment after outpatient surgery. Ann Surg 255:1093-1099, 2012

42. Patel AP, Koltz MT, Sansur CA, Gulati M, Hamilton DK: An 
analysis of deep vein thrombosis in 1277 consecutive neurosurgical patients undergoing routine weekly ultrasonography. J Neurosurg 118:505-509, 2013

43. Prell J, Rachinger J, Smaczny R, Taute BM, Rampp S, Illert $\mathrm{J}$, et al: D-dimer plasma level: a reliable marker for venous thromboembolism after elective craniotomy. J Neurosurg 119:1340-1346, 2013

44. Raabe A, Gerlach R, Zimmermann M, Seifert V: The risk of haemorrhage associated with early postoperative heparin administration after intracranial surgery. Acta Neurochir (Wien) 143:1-7, 2001

45. Ramanan B, Gupta PK, Sundaram A, Lynch TG, MacTaggart JN, Baxter BT, et al: In-hospital and postdischarge venous thromboembolism after vascular surgery. J Vasc Surg 57:1589-1596, 2013

46. Rasouli MR, Jaberi MM, Hozack WJ, Parvizi J, Rothman RH: Surgical care improvement project (SCIP): has its mission succeeded? J Arthroplasty 28:1072-1075, 2013

47. Sawaya R, Glas-Greenwalt P: Postoperative venous thromboembolism and brain tumors: Part II. Hemostatic profile. J Neurooncol 14:127-134, 1992

48. Sawaya R, Highsmith RF: Postoperative venous thromboembolism and brain tumors: Part III. Biochemical profile. J Neurooncol 14:113-118, 1992

49. Sawaya R, Zuccarello M, Elkalliny M, Nishiyama H: Postoperative venous thromboembolism and brain tumors: Part I. Clinical profile. J Neurooncol 14:119-125, 1992

50. Scales DC, Riva-Cambrin J, Wells D, Athaide V, Granton JT, Detsky AS: Prophylactic anticoagulation to prevent venous thromboembolism in traumatic intracranial hemorrhage: a decision analysis. Crit Care 14:R72, 2010

51. Scarborough JE, Cox MW, Mureebe L, Pappas TN, Shortell CK: A novel scoring system for predicting postoperative venous thromboembolic complications in patients after open aortic surgery. J Am Coll Surg 214:620-628, 2012

52. Smith SF, Biggs MT, Sekhon LH: Risk factors and prophylaxis for deep venous thrombosis in neurosurgery. Surg Technol Int 14:69-76, 2005

53. Tran BH, Nguyen TJ, Hwang BH, Vidar EN, Davis GB, Chan LS, et al: Risk factors associated with venous thromboem- bolism in 49,028 mastectomy patients. Breast 22:444-448, 2013

54. Tyson MD, Castle EP, Humphreys MR, Andrews PE: Venous thromboembolism after urological surgery. J Urol 192:793797, 2014

55. Tzeng CW, Katz MH, Fleming JB, Pisters PW, Lee JE, Abdalla EK, et al: Risk of venous thromboembolism outweighs post-hepatectomy bleeding complications: analysis of 5651 National Surgical Quality Improvement Program patients. HPB (Oxford) 14:506-513, 2012

56. Vaitkus PT, Leizorovicz A, Cohen AT, Turpie AG, Olsson CG, Goldhaber SZ: Mortality rates and risk factors for asymptomatic deep vein thrombosis in medical patients. Thromb Haemost 93:76-79, 2005

57. Wang Y, Eldridge N, Metersky ML, Verzier NR, Meehan TP, Pandolfi MM, et al: National trends in patient safety for four common conditions, 2005-2011. N Engl J Med 370:341-351, 2014

58. Zwicker JI, Liebman HA, Bauer KA, Caughey T, Campigotto F, Rosovsky R, et al: Prediction and prevention of thromboembolic events with enoxaparin in cancer patients with elevated tissue factor-bearing microparticles: a randomizedcontrolled phase II trial (the Microtec study). Br J Haematol 160:530-537, 2013

\section{Author Contributions}

Conception and design: both authors. Acquisition of data: Kimmell. Analysis and interpretation of data: Kimmell. Drafting the article: Kimmell. Critically revising the article: both authors. Reviewed submitted version of manuscript: Kimmell. Statistical analysis: Kimmell. Study supervision: Jahromi.

\section{Correspondence}

Kristopher T. Kimmell, Department of Neurosurgery, University of Rochester Medical Center, 601 Elmwood Ave., Box 670, Rochester, NY 14642. email: kristopher_kimmell@urmc. rochester.edu. 